\title{
CARACTERIZAÇÃO DE BACTÉRIAS DOS GÊNEROS MIMA E HERELLEA (Tribo Mimeae, DeBord, 1942) 1) Propriedade morfo-bioquímicas e sensibilidade aos antibióticos ${ }^{1}$
}

\author{
ALTAIR A. ZEBRAL * e ERNESTO HOFER * \\ Iustituto Oswaldo Cruz, Rio de Janeiro, Guanabara
}

Ao estudar bacteriològicamente alguns casos de conjuntivites $\mathrm{e}$ vaginites, DeBord, em 1939, isolou bactérias Gram negativas com características peculiares, permitindo posteriormente, em 1942, criar a tribo Mimeae com os gêneros Mima, Herellea e Colloides, sendo êste último enquadrado atualmente no Grupo Citrobacter, da família Enterobacteriaceae. O gênero Mima compreendia a espécie polymorpha com a variedade oxidans e Herellea a espécie vaginicola.

Os têrmos Mima e Herellea têm sido contestados por inúmeros autores (Pickett e Manclark, 1965; Baumann e col., 1968a; Leduc e col., 1969) apesar do seu uso freqüente na literatura científica. Outras designações são usadas; Moraxella (Lwoff, 1939), Acbromobacter (Brisou, 1953), Acinetobacter (Brisou e Prèvot, 1954); Diplococcus Lingelsheim, 1908); Bacterium (Schaub e Hauber, 1948); Cytophaga (Lautrop, 1961); Neisseria (Lemoigne e col., 1962); B5W (Stuart e col., 1949).

O número de trabalhos sôbre a chamada tribo Mimeae, desde 0 ano de 1939, tem aumentado progressivamente na literatura mundial, e, apesar disso, muito pouco se sabe sôbre êstes microrganismos que parecem estar amplamente distribuídos na superfície da terra, com isolamentos freqüentes a partir de materiais humanos, nas mais variadas

1 Recebido para publicação a 16 de outubro de 1970.

* Departamento de Microblologia e Imunologia, Laboratório de Bacteriologia. 
Mem. Inst. Oswaldo Cruz, 69 (2), 1971

áreas gecgráficas: Andureau (1940), na França; Brooke \& Markus (1951), na Dinamarca; DeBord (1939), nos E.U.A.; Travassos (1960) e Vernin-Ciconelli (1968) no Brasil; Roby (1954) no Vietnan; Prakash \& col. (1963) na India; Liu-Kuei-Chih \& col., (1966) na China Continental; Lothe \& Griffin, (1965) na Uganda.

Muitos pesquisadores já assinalaram o isolamento dêsses microrganismcs a partir de: solo, Piechaud \& col. (1951); Lemoigne \& col. (1952); Casellas (1968); animais, Ellis (1961); água de rio Kenner \& Kobler (1956); alimentos derivados do leite, Koburger (1964); alimentos frescos, pasteurizados, pré-cozidos e congelados, Snodgrass \& col. (1967).

Ùltimamente, as bactérias Mima e Herellea têm sido islodas com relativa freqüência de processos infecciosos, estando relacionadas como agentes etiológicos de: meningites, Olafsson e col. (1958), Irving \& Herrick (1967), DeBord (1948); septicemias, Faust \& Hood (1949), Pedrinazzi \& Stangalini (1968); osteomielites, Brodies \& Anderson (1963) ; pneumonia, Glick \& col. (1959); infecção brônquica, Henriksen (1951); lesões cardio-vasculares, Minzter (1956); King \& col. (1963); infecções genito-urinárias, DeBord (1939), Svihus \& col. (1961), Travasses (1960), Vernin \& Ciconelli (1968), Inclan \& col. (1965), Gilardi (1968) Irving \& Herrick (1967), Bret \& Durieu (1961). Outros tipos

TABELA I

Amostras de Mima e Herellea isoladas por Irving \& Herrick (1967)

\begin{tabular}{l|c|c|c}
\multicolumn{1}{c|}{ Fonte } & “Mima polymorpha” & Herellea vaginicola & Total \\
\hline Escarro & 18 & 41 & 59 \\
\hline Urina & 9 & 34 & 43 \\
\hline Sangue & 22 & 2 & 24 \\
\hline Pele e feridas & 9 & 9 & 18 \\
\hline Ginecológico & 4 & 6 & 10 \\
\hline Nariz e garganta & 2 & 7 & 9 \\
\hline Outros & 5 & 7 & 12 \\
\hline \multicolumn{1}{c|}{ To t a l } & 69 & 106 & 175 \\
\hline
\end{tabular}




\section{TABELA Tr}

Amostra de Mima e Herellea isoladas por Gilardi (1968)

\begin{tabular}{l|c}
\multicolumn{1}{c|}{ Fonte } & N. de amostras \\
\hline Feridas & 59 \\
\hline Urina & 48 \\
\hline Escarro & 14 \\
\hline Úlcera diabética & 7 \\
\hline Abcessos & 6 \\
\hline Garganta & 3 \\
\hline Traquéia & 3 \\
\hline Osteomielite & 3 \\
\hline Uretra & 22 \\
\hline Outros & 167 \\
\hline To t a l & \\
\hline
\end{tabular}

de infecção também foram citados. 1 tabela I (Irving \& Herrick, 1967) e a Tabela II (Gilardi, 1968) mostram várias fontes de isolamento de material de origem humana.

Em nosso meio são raros os trabalhos que relatam o isolamento dêstes microrganismos, destacando-se, inicialmente, Travassos (1960) que isolou 5 amostras, a partir de casos de meningite, infecção pilocutânea, pseudo-gonorréia e infecção urinária; Vernin \& Ciconelli (1968), 4 amostras de casos de pseudo-gonorréia, urina e hemocultura e, Casellas (1968), obteve 24 amostras de solo, que foram classificados como pertencentes ao grugo Lwoff-glycidolitica (Pièchaud \& Sècond, 1956) .

No presente trabalho estudam-se as características morfológicas e bioquímicas de 19 amostras, sendo 17 oriundas de material clínico humano e 2 de água de esgôto, além da sensibilidade aos antibióticos. 


\section{MATERIAL E MÉTODOS}

Os materiais clínicos humanos foram provenientes de ambulatórios e hospitais e, as amostras de água de esgôto, provenientes de material colhido no afluente de uma estação de tratamento da cidade. A tabela III mostra a origem do material clínico humano, inclusive os da água de esgôto.

\section{TABELA III}

Distribuição das amostras de Mima e Herellea isoladas

\begin{tabular}{|c|c|c|c|c|}
\hline Fonte & $\begin{array}{c}\text { Mima } \\
\text { polymorpha } \\
\text { var. oxidans }\end{array}$ & $\begin{array}{c}\text { Mima } \\
\text { polymorpha }\end{array}$ & $\begin{array}{l}\text { Herellea } \\
\text { vaginicola }\end{array}$ & Total \\
\hline Secreção uretral & - & 1 & 5 & 6 \\
\hline Urina & - & 2 & 3 & 5 \\
\hline Secreção vaginal & 3 & - & - & 3 \\
\hline Naso-faringe & - & 1 & - & 1 \\
\hline Acne & - & - & 1 & 1 \\
\hline $\begin{array}{l}\text { Fistula operató- } \\
\text { ria abrominal }\end{array}$ & - & - & 1 & 1 \\
\hline Água de esgôto & 2 & - & - & 2 \\
\hline $\mathrm{T} \circ \mathrm{t}$ a $\mathrm{l}$ & 5 & 4 & 10 & 19 \\
\hline
\end{tabular}

\section{Isolamento}

Todos os isolamentos foram obtidos a partir dos seguintes meios: ágar-simples, ágar-sangue, ágar-chocolate, meio ágar-tripticase soy (B.B.L.), meio E.M.B. ágar (Difco). Os meios líquidos utilizados incluem o caldo simples (com água de carne) e o caldo tripticase soy (B.B.L.). As amostras foram sempre mantidas em caldo e ágar inclinado e repicadas cada 2 semanas. $O$ contrôle da pureza das culturas foi feito pela bacterioscopia corada pelo método de Gram, além da semeadura em placas de ágar-simples. 


\section{Identificação das amostras}

Foi baseada nos trabalhos de DeBord, 1939, 1942, Irving \& Herrick, 1967; Gilardi, 1968; Baumann \& col. 1968 (a) e (b), comparando os dadcs obtidos com c comportamento de amostras padrões de Mima polymorpha € Herellea vaginicola provenientes do Instituto de Microbiologia Médica da Universidade Federal do Rio de Janeiro.

\section{Aspectos morfológicos}

A morfologia celular foi observada através esfregaço corado pelo método de Gram, a partir de cultura em caldo simples, com 20-24 horas de incubação a $37^{\circ} \mathrm{C}$ e também pela microscopia de fase. $\mathrm{O}$ aspecto cclonial foi observado pela semeadura em meio de E.M.B. ágar (Difco) e ágar-sangue.

\section{Reações bioquímicas}

As provas e os meios empregados incluiam: produção de acidez em meio com água triptosada contendo $1 \%$ de glicose, lactose, sacarose, manita, xilose, arabinose, maltose, sorbitol, galactose, ramnose, celobiose, dulcitol, manose, salicina, utilizando-se o azul de bromo timol como indicador de $\mathrm{pH}$, prolongando-se a incubação por 15 dias para a leitura final. Os mesmos açúcares foram estudados no seu comportam€nto usando-se o meio básicc mineral tendo como fonte de carbono o acetato de sódio, como fonte de nitrogênio o cloreto de amônio, e ccmo indicador de reação o vermelho de fencl; ataque ao tartarato de sódio e potássio em meio sólido de acôrdo com Jordan (1928), sendo usada também a fórmula líquida; comportamento no meio com $10 \%$ de lactose em ágar inclinado com vermelho de fenol segundo Chilton \& Fulton (1946); observação da oxidação ou fermentação da glicose em meio de Hugh-Leifson (1953), sem acrescentar vaspar ou óleo mineral; produção de indol em água peptonada, utilizando-se o reativo de Kovacs para sua evidenciação; prova de VM-VP em meio de ClarckLubs; empregando-se a técnica de Barrit para VP; utilização do citrato em meio de Koser; comportamento em meio de KCN segundo Moeller (1954); redução de nitrato a nitrito em caldo nitratado, utilizando-se o reativo de Griess-Ilosva; atividade gelatinásica em meio com $12 \%$ de gelatina; reação de oxidase, de acôrdo com a técnica de Kovacs (1956); os testes de produção de gás sulfídrico, urease e mobilidade foram observados em meio de Costa e Vernin (1955); a confirmação desta última prova foi feita em meio semi-sólido segundo fórmula de 
Kauffmann e, em microscopia de fase; a capacidade hemolisante foi determinada em meio de D.S.T. ágar base (Oxoid), acrescido de sangue de carneiro citratado na proporção de $5 \%$; produção de catalase, em ágar inclinado, utilizando-se água oxigenada a $3 \%$ e produção de pigmento em caldo simples, ágar-simples e ágar-amido. O tempo de incubação, a técnica e os reagentes das provas obedeceram às recomendações do "Manual of Microbiological Methods" da "Society of American Bacteriologists (1957)". Todos os carboidratos foram esterilizados por filtração e juntados assèpticamente aos meios de modo a se ter, uma concentração final de $1 \%$ do açúcar. Para os repiques utilizou-se a alça de platina com diâmetro interno de $4 \mathrm{~mm}$ e agulha de platina quando havia indicação.

\section{Sensibilidade aos antibióticos}

A sensibilidade aos antibióticos foi estudada pela técnica dos discos e da diluição do antibiótico em meio sólido. Neste último processo utilizou-se 0,1 e 1 unidade por $\mathrm{ml}$ de um produto comercial contendo penicilina $G$ potássica (300.000 unidades) e penicilina procainada (100.000 unidades). Foram empregados os discos Oxoid, código n. ${ }^{\circ}$ $2024 \mathrm{~F}$, tipo urinário e os polidiscos antibióticos segundo Victor Lorian, conseguindo-se dêste modo testar a sensibilidade às drogas relacionadas nas tabelas VII e VIII. O meio empregado foi o D.S.T. ágar Base Oxoid e, o inóculo a partir de cultura em caldo simples de 24 horas a $37^{\circ} \mathrm{C}$ e espalhamento com swab estéril. Após a semeadura na superfície das placas, foi eliminado o excesso de umidade pela incubação a $37^{\circ} \mathrm{C}$ durante $30-60$ minutos. Leitura com 24 horas, tendo-se, como critério de sensibilidade, o tamanho do halo de inibição, de acôrdo com os padrões utilizados para os polidiscos antibióticos. A sensibilidade das amostras à mistura de penicilina foi testada em meio HIA ágar, Baumann \& col., (1968a). Para obtenção das concentrações acima mencionadas o antibiótico foi acrescentado ao meio sólido fundido quando a temperatura caía a $40^{\circ} \mathrm{C}$, antes do vazamento das placas. $O$ inóculo para a semeadura das placas com antibióticos foi obtido de culturas de 24 horas a $37^{\circ} \mathrm{C}$ em meio HIB, Balmann \& col. (1968a), usando-se semear 4 amostras em cada placa.

\section{RESULTADOS}

Morfologia celular e colonial - Em caldo simples após 24 horas de incubação a $37^{\circ} \mathrm{C}$, Mima e Herellea foram consistentemente Gram negativo. Mima Polymorpha e Herellea vaginicola apresentaram-se mais 
regularmente nas formas cocoides ou diplococoides com pequeno grau de pleomorfismo, enquanto que, Mima Polymorpha var. oxidans apresentou-se mais regularmente na forma bacilar e com pleomorfismo mais acentuado (Tabela IV). As colônias em ágar-sangue e EMB (Difco), foram, de modo geral, circulares, convexas, bordo inteiro, lisas, opacas, tonalidade branco-pérola a creme no ágar-sangue e azulada a lilás no EMB. Predominantemente, as colônias de Herellea vaginicola e Mima Polymorpha, sempre foram bem maiores que Mima polimorpha var. oxidans. No meio de EMB ágar (Difco) esta última apresentou colônias muito pequenas, só bem visíveis à luz refletida, após 48 horas a $37^{\circ} \mathrm{C}$. Nenhurra das amostras estudadas demanstrou capacidade hemolítica para sangue citratado de carneiro e, caracteristicamente, Mima polimorpha var. oxidans cresceu lentamente, em comparação com as outras. Independentemente do gênero e da espécie, algumas amostras dão cclônias mucoides $e$, em caldo simples, após 1 a 2 semanas, à temperatura ambiente, apresentam uma massa de depósito de material gelatinoso. As propriedades bioquímicas são vistas nas Tabelas V e VI e a sensibilidade aos antibióticos nas Tabelas VII, VIII e IX.

\section{TABELA IV}

Aspectos morfológicos das amostras de Mima e Herellea

\begin{tabular}{|c|c|c|c|}
\hline "Gênero-espécie" & $\begin{array}{c}\text { Mima polymorpha } \\
\text { var. oxidans } \\
\text { (5 amostras) }\end{array}$ & $\begin{array}{l}\text { Mima polymorpha } \\
\quad(4 \text { amnstras })\end{array}$ & $\begin{array}{c}\text { Herellea } \\
\text { vaginicola } \\
\text { (10 amostras) }\end{array}$ \\
\hline $\begin{array}{l}\text { Propriedade } \\
\text { tintorial (Gram) }\end{array}$ & $\begin{array}{l}\text { Predominan- } \\
\text { temente } \\
\text { Gram negativo }\end{array}$ & Idem & Idem \\
\hline $\begin{array}{l}\text { Morfologia : } \\
\text { a) celular (1) }\end{array}$ & $\begin{array}{l}\text { bacilar, intenso } \\
\text { pleomorfismo }\end{array}$ & $\begin{array}{l}\text { cocoide, } \\
\text { diplococoide, } \\
\text { apresenta } \\
\text { pleomorfismo }\end{array}$ & $\begin{array}{l}\text { cocoide, } \\
\text { diplococoide, } \\
\text { pleomorfismo } \\
\text { mais raro }\end{array}$ \\
\hline b) colonial (2) & $\begin{array}{l}\text { colônia pequena, } \\
\text { geralmente } \\
\text { mucoide, circular } \\
\text { inteira e bem } \\
\text { convexa }\end{array}$ & $\begin{array}{l}\text { colônia grande } \\
\text { pode ser mucoide. } \\
\text { circular inteira, } \\
\text { pode ter super- } \\
\text { fície bem elevada }\end{array}$ & $\begin{array}{l}\text { colônia grande, } \\
\text { geralmente } \\
\text { mucoide, circular, } \\
\text { inteirą e superfí- } \\
\text { cie elevada }\end{array}$ \\
\hline
\end{tabular}

(1) Aspectos observados após 24 horas a $370 \mathrm{C}$ em caldo simples.

(2) Aspectos observados em ágar-sangue, após 24 horas a $370 \mathrm{C}$. 
TABELA V

Características das amostras de Mima e Herellea

\begin{tabular}{|c|c|c|c|c|c|c|c|}
\hline Meio teste ou substrato & \multicolumn{3}{|c|}{$\begin{array}{c}\text { Mima polymorpha } \\
\text { var. oxidans } \\
\text { (5 amostras) }\end{array}$} & \multicolumn{2}{|c|}{$\begin{array}{l}\text { Mima polymorpha } \\
\text { (4 amostras) }\end{array}$} & \multicolumn{2}{|c|}{$\begin{array}{l}\text { Herellea vaginicola } \\
\quad \text { (10 amostras) }\end{array}$} \\
\hline Meio de Costa-Vernin (C.V.) & \multicolumn{3}{|c|}{ reação de alcalinidade (5) } & \multicolumn{2}{|c|}{ reação de alcalinidade (4) } & \multicolumn{2}{|c|}{ reação de alcalinidade (10) } \\
\hline$\overline{\text { Meio de Teague }}$ & $+(4)$ & cres. & $-(1)$ & $+(4)$ & & $+(10)$ & nte \\
\hline Hemólise & & & $-(5)$ & & $-(4)$ & & $-(\overline{10})$ \\
\hline Catalase & $+(5)$ & & & $+(4)$ & & $+(10)$ & \\
\hline Gelatina & $+(3)$ & & $-(2)$ & $+(2)$ & $-(2)$ & $+(1)$ & $-(9)$ \\
\hline Indol - & & & $-(5)$ & & $-(4)$ & & $-(10)$ \\
\hline$\overline{\mathrm{VM}}$ & & & $-(5)$ & & $-(4)$ & & $-(10)$ \\
\hline VP & & & $-(5)$ & & -(4) & & $-(10)$ \\
\hline Citrato Koser & $+(1)$ & & $-(4)$ & $+(1)$ & $-(3)$ & $+(10)$ & \\
\hline $\mathbf{K C N}$ & $+(3)$ & & $-(2)$ & $+(2)$ & -(2) & $+(10)$ & \\
\hline$\overline{\mathrm{H} 2 \mathrm{~S}}$ & & & $-(5)$ & & $-(4)$ & & $-(10)$ \\
\hline NO3-NO2 & $+(2)$ & & $-(3)$ & & $-(4)$ & & $-(10)$ \\
\hline Mobilidade & & & $-(5)$ & & $-(4)$ & & $-(10)$ \\
\hline Öxidase & $+(5)$ & & & & 二(4) & & $-(10)$ \\
\hline Pigmento & & & $-(5)$ & & $-(4)$ & & $-(10)$ \\
\hline Glicose $(\mathbf{H}-\mathbf{L})$ & & & $-(5)$ & & $-(4)$ & $+(\mathbf{1 0})$ & \\
\hline Lactose $10 \%$ & & & $-(5)$ & & $-(4)$ & $+(10)$ & \\
\hline
\end{tabular}

Cres. $=$ Crescimento.

$(\mathrm{H}-\mathrm{L})=$ Hughs-Leifson

$+=$ Resultado do teste positivo.

- = Resultado do teste negativo. 
TABELA VI

Oxidação de carboídratos em meio nitrogenado complexo e em meio sintético

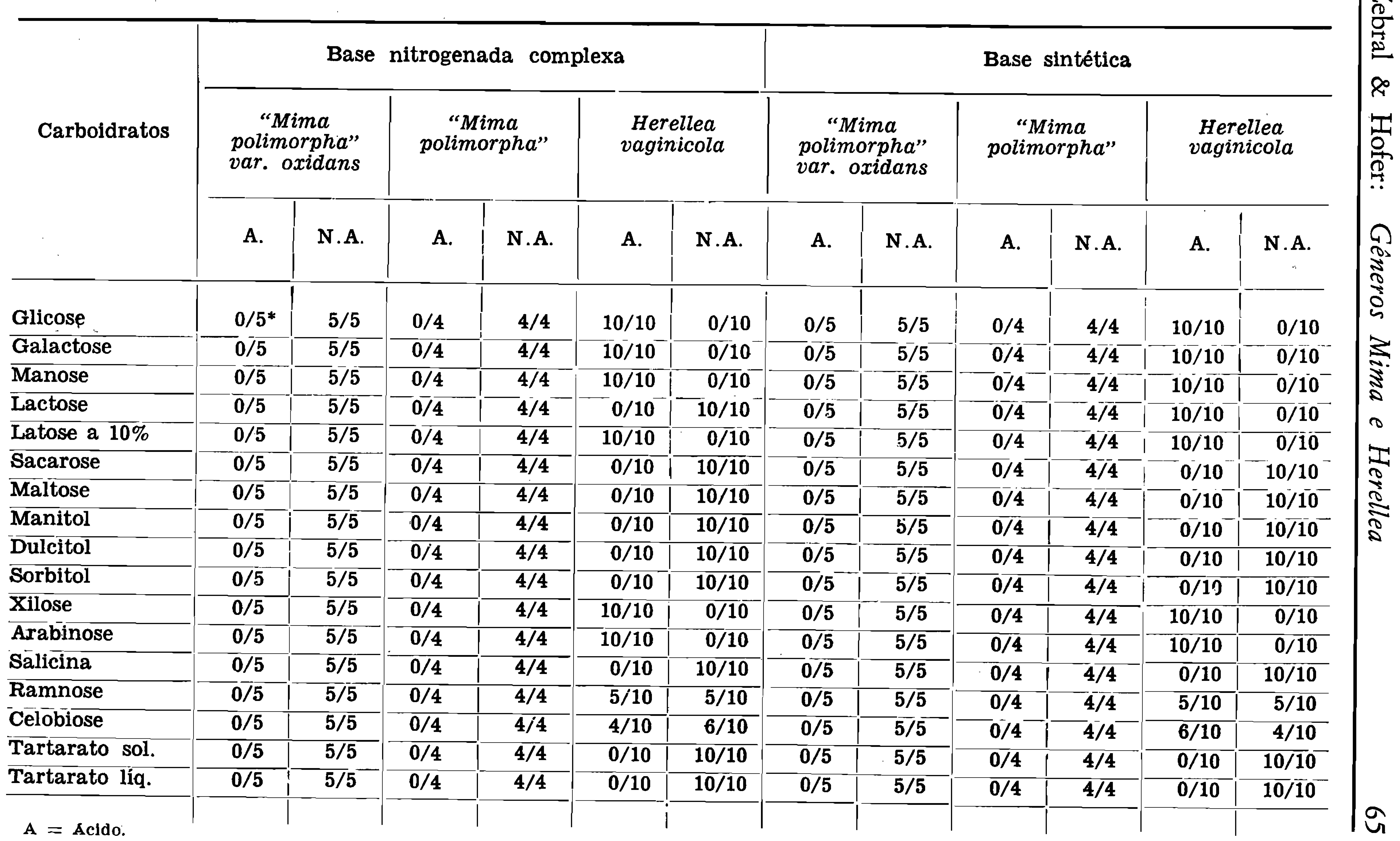

$A=$ Acido:

NA = Nenhuma mudanca no indicador.

* O numerador das frações indica o comportamento das amostras e o denominador o número de amostras testadas. 


\section{DISCUSSÃO}

As características morfológicas de Mima e Herellea permitem uma semelhança com as Neisserias, enquanto que fisiológica e bioquìmicamente são passíveis de serem confundidas com outras bactérias, principalmente as dos gêneros Pseudomonas não pigmentadas, Alcaligenes e Moraxella.

Muitos dos trabalhos existentes sôbre isolamento e estudos das propriedades morfobioquímicas dessas bactérias apresentaram resultados diferentes e, devido à semelhança com outros gêneros bacterianos, resultou o aparecimento de dezenas de nomes, como se pode verificar na Tabela $\mathbf{X}$. Por outro lado, ainda não há acôrdo quanto à situação taxonômica conforme se vê na 6. ${ }^{a}$ Edição do "Manual Bergey" Breed \& col. (1948), onde a Tribo Mimeae estava colocada na Família Parvobacteriaceae e na 7. ${ }^{\text {a }}$ Edição, Breed \& col. (1957), não mais constou a Tribo Mimeae com os gêneros Mima e Herellea.

Nos estudos sôbre a produção de ácido a partir de hidrocarbonados pelas bactérias dos gêneros Mima e Herellea, os autores têm observado dualidade de resultados quando são empregados meios complexos nitrogenados e meios sintéticos (Gilardi, 1968 e Baumann \& col., 1968b). Este fato parece ser devido à produção de substâncias alcalinas oriun-

TABELA VII

Sensibilidade de Mima e Herellea aos discos Oxoides, código n. ${ }^{\circ}$ 2024-E, tipo urinário *

\begin{tabular}{|c|c|c|c|c|}
\hline Antibióticos & $\begin{array}{l}\text { Concen- } \\
\text { traçōes }\end{array}$ & $\begin{array}{l}\text { Mima } \\
\text { polymorpha } \\
\text { var. oxidans } \\
\text { (5 amostr.) }\end{array}$ & $\begin{array}{c}\text { Mima } \\
\text { polymorpha } \\
4 \text { amostr.) }\end{array}$ & $\begin{array}{c}\text { Herellea } \\
\text { vaginicola } \\
10 \text { (amostr.) }\end{array}$ \\
\hline Cloranfenicol & $50 \mathrm{ug}$ & 100 & 100 & 70 \\
\hline Ampicilina & $25 \overline{\mathrm{ug}}$ & 50 & 75 & 80 \\
\hline Tetraciclina & $50 \mathrm{ug}$ & 100 & 100 & 100 \\
\hline Ácido nalidíxico & $30 \mathrm{ug}$ & 100 & 10 & 100 \\
\hline Gentamicina & $10 \mathrm{ug}$ & $\overline{100}$ & 100 & 100 \\
\hline$\overline{\text { Bactrin }}$ & $25 \mathrm{ug}$ & 40 & 75 & 70 \\
\hline Nitrofurantoina & $200 \mathrm{ug}$ & 40 & 50 & 0 \\
\hline Sulfadiazina & $300 \mathrm{ug}$ & 20 & 0 & 30 \\
\hline
\end{tabular}

* Percentagens de sensíveis (sensivel e pouco sensível). 
das de elementos complexos nitrogenados do meio, neutralizando os ácidos formados. Deve-se considerar, ainda, que a produção de ácido a partir da glicose em meios de cultura sem cutra fonte de carbono, tem sido usado como o maior critério taxonômico para êste grupo de bactérias e, no entanto, a capacidade de produzir ácidos a partir da glicose, raramente denota utilização dêste açúcar como uma fonte de carbcno para o crescimento, Baumann \& col. (1968b). Por êstes motivos, os testes para a produção de ácido a partir da glicose devem ser realizados em meios sintéticos que possuam uma outra fonte de carbono para suportar o crescimento da bactéria.

\section{TABELA VIII}

Sensibilidade de Mima e Herellea aos Polidiscos (21)*

\begin{tabular}{|c|c|c|c|c|}
\hline Antibióticos & $\begin{array}{l}\text { Soncen- } \\
\text { trações }\end{array}$ & $\begin{array}{c}\text { Mima } \\
\text { polymorpha } \\
\text { var. oxidans } \\
(5 \text { amostr. })\end{array}$ & $\begin{array}{c}\text { Mima } \\
\text { polymorpha } \\
\text { (4 amostr.) }\end{array}$ & $\begin{array}{c}\text { Herellea } \\
\text { vagınicola } \\
\text { (10 amostr.) }\end{array}$ \\
\hline Aureomicina & $15 \mathrm{ug}$ & 40 & 25 & 10 \\
\hline Cloranfenicol & $20 \mathrm{ug}$ & 100 & $10 n$ & 20 \\
\hline Eritromicina & $15 \mathrm{ug}$ & 0 & 25 & 0 \\
\hline Gabromicina & $40 \mathrm{ug}$ & 80 & 100 & $100^{-}$ \\
\hline Kanamicina & $30 \mathrm{ug}$ & 100 & 100 & 100 \\
\hline Neomicina & $25 \mathrm{ug}$ & 80 & 100 & 100 \\
\hline Novobiocina & $25 \mathrm{ug}^{-}$ & 20 & 50 & 50 \\
\hline Colistin & $45 \mathrm{ug}$ & 100 & 100 & 100 \\
\hline Penicilina & $5 \bar{u}$ & 0 & 0 & 0 \\
\hline Rifomicina & $10 \mathrm{ug}$ & 20 & 50 & 40 \\
\hline Rovamicina & $35 \mathrm{ug}$ & 80 & $100^{-}$ & $60^{-}$ \\
\hline Oxacilina & $5 \mathrm{ug}$ & 0 & 0 & 0 \\
\hline Estreptomicina & $15 \mathrm{ug}$ & 40 & 50 & 70 \\
\hline Terramicina & $20 \mathrm{ug}$ & 60 & 50 & 90 \\
\hline Lincomicina & $10 \mathrm{ug}$ & 0 & 0 & 0 \\
\hline Wintomylon & $20^{-} \mathrm{ug}^{-}$ & 100 & 75 & 80 \\
\hline Furadantin & $50^{-} \mathrm{ug}^{-}$ & 20 & 0 & 0 \\
\hline Keflin (1) & 一 & 20 & 25 & 0 \\
\hline Ilosene $(2)$ & - & 40 & 50 & 30 \\
\hline
\end{tabular}

* Percentagem de sensiveis (sensivel e pouco sensivel).

(1) e (2) Discos de Laboratório Lilly. 
TABELA IX

Sensibilidade de Mima e Herellea a 0,1 e 1 Unidade/ml de Penicilina *

\begin{tabular}{|c|c|c|c|c|c|c|c|c|c|}
\hline \multirow{2}{*}{$\begin{array}{l}\text { Fenicilina } \\
\mathrm{U} / \mathrm{ml}\end{array}$} & \multicolumn{3}{|c|}{ Mima polymorpha var. oxidans } & \multicolumn{3}{|c|}{ Mima polymorpha } & \multicolumn{3}{|c|}{ Herellea } \\
\hline & Positivo & Negativo & Total & Positivc & Negativo & Total & Positivo & Negativo & Total \\
\hline 0,1 & 2 & 3 & 5 & 2 & 2 & 4 & 10 & - & 10 \\
\hline 1 & 2 & 3 & 5 & 1 & 3 & 4 & 8 & 2 & 10 \\
\hline
\end{tabular}

* Associação de Penicilina G potássica (300.000 U) e Penicilina procainada (100.000 U). Positivo - Crescimento.

Negativo - Ausência de crescimento. 
TABELA $\mathbf{X}$

Sinônimos dos membros da Tribo Mimeae, DeBord, 1942 (adaptado de

Casellas, 1968 e Pickett e Manclark,) (1967)

\begin{tabular}{|c|c|}
\hline Membro & Sinônimos \\
\hline Mima polymorpha var. oxidans & $\begin{array}{l}\text { Moraxella duplex } \\
\text { Moraxella non liquefaciens } \\
\text { Moraxella osloiensis }\end{array}$ \\
\hline Mima polymorpha & $\begin{array}{l}\text { Achromobacter lwoffii } \\
\text { Acinetobacter lwoffii } \\
\text { Cytophaga lwoffii } \\
\text { Acinetobacter polymorpha } \\
\text { Moraxella lwoffii } \\
\text { Achromobacter metalcaligenes }\end{array}$ \\
\hline Herellea vaginicola & $\begin{array}{l}\text { Bacterium anitratum } \\
\text { D5W } \\
\text { Achromobacter anitratus } \\
\text { Diplococcus mucosus } \\
\text { Moraxella lwoffii var. glucidolytica } \\
\text { Acinetobacter anitratus } \\
\text { Moraxella vaginicola } \\
\text { Moraxella glucidolytica } \\
\text { Cytophaga anitratum } \\
\text { Lingelsheimia anitratum } \\
\text { Alcaligenes metalcaligenes } \\
\text { Acinetobacter winogradsky } \\
\text { Neisseria winegradsky }\end{array}$ \\
\hline
\end{tabular}

Atendendo a estas verificações é que utilizamos uma base sintética tendo como fonte de nitrogênio o cloreto de amônio e como fonte de carbono e acetato de sódio, acrescido dos íons ferro $(\mathrm{Fe})$, magnésic $(\mathrm{Mg})$ e sódio $(\mathrm{Na})$, para a observação da produção de ácidos a partir da glicose e, também, dos outros carboidratos.

Com esta técnica, as culturas de Mima polymorpha var. oxidans não atacaram nenhum carboidrato tanto em meio nitrogenado complexo 
como na base sintética utilizada; Mima polymorpha também não revelou nenhuma atividade glicidolítica, quer na base nitrogenada complexa, quer na base sintética. Herellea vaginicola sempre produziu ácido, sem gás, $\in \mathrm{m}$ meio nitrogenado complexo a partir de glicose, galactose, manose, arabinose, xilose, lactose a $10 \%$ e ataca irregularmente a ramnose e celobicse. Os mesmos resultados foram observados em meio sintéticc, devendo-se ressaltar que a lactose tanto a 1 como a $10 \%$ foi metabolizada, com produção de ácido por tôdas as amostras estudadas.

Alguns dêstes resultados estão de acôrdo com os obtidos por Gilardi (1963), Travassos (1960) e Vernin \& Ciconelli (1968); sacarose, manitcl, dulcitcl e salicina jamais foram atacados por qualquer uma das amostras de Mima e Herellea de origem humana estudada. H. vaginicola sempre produziu áciỏo a partir de glicose e lactose a $10 \%$, sendo que êste último foi cbservado por Gilardi (1968) apenas em base nitrogenada complexa. Nєste meio e em base sintética, nenhuma de nossas amcstras de $M$. polymorpha apresentou atividade glicidolítica. No entanto, 9 (nove) açúcares foram atacados irregularmente pelas amostras estudadas por Gilandi (1968). Esste fato deve ser devido às diferentes bases sintéticas, uma vêz que a utilizada por êste autor não possuia outra fonte de carbono que não o carboidrato. Efetivamente, $M$. polymorpha var. oxidans não apresenta nenhuma atividade glicidolítica.

O emprêgo do meio de Hugh-Leifson (1953), permitiu distinguir um dos dois processos metabólicos (oxidação ou fermentação) fato a que alguns autores não fazem referência. Foi possível constatar que sòmente $H$. vaginicola apresenta metabolismo oxidativo, produzindo ácido a partir da glicose.

A produção de pigmento fci estuảada durante um longo período (6 meses), empregando-se caldo simples, ágar-inclinado e ágar-amido inclinado, de acôrdo com o "Manual of Microbiological Methods" (Society of American Bacteriologists). Esta observação estava relacionada com a manutenção das culturas. Os repiques eram feitos de $15 / 15$ dias e após passagem na estufa a $37^{\circ} \mathrm{C}$ por 24 horas, permaneciam à temperatura ambiente e na presença da luz difusa. Nenhuma das amostras desenvolveu pigmentos.

Dcs inúmeros trabalhos publicados sôbre Mima e Herellea, verificase haver perfeito acôrdo entre os pesquisadores na maioria das características bacteriológicas estudadas, havendo, no entanto, resultados contraditórios em algumas propriedades importantes. 
A sensibilidade aos antibióticos apresentou resultados bem diferentes daqueles observados por Gilardi (1968). No trabalho dêste autor, Mima polymorpha var. oxidans foi sensível a 17 das 19 substâncias testadas. Em nossos dados (Tabela VII e VIII) não encontramos esta característica. Das 19 drogas testadas só houve sensibilidade a quatro. Mesmo utilizando os discos Oxoid, tipo urinário, no qual a concentração é duas ou três vêzes superior à dos discos comuns, de 8 substâncias só 4 mostraram sensibilidade: cloranfenicol, tetraciclina, gentamicina e ácido nalidíxico. No entanto, quanto à $H$. vaginicola e $M$. polymorpha, a grande variação de sensibilidade às diversas substâncias foi confirmada. Um resultado importante, idêntico ao observado por Gilardi (1968), Travassos (1960) e Vernin \& Ciconelli (1968) é que as amostras por nós estudadas foram sensíveis à kanamicina, colistin, necmicina e gabromicina (Tabela VIII).

Nas condições do presente trabalho, não observamos a tão citada sensibilidade da Mima polymorpha var, oxidans à penicilina, Gilardi (1968), Baumann \& col. (1968). Das amostras por nós isoladas, 3 foram sensíveis a 0,1 e 1 unidade, e 2 amostras foram resistentes (Tabela IX). M. polymorpha variou na sensibilidade e $H$. vaginicola é regularmente resistente à estas duas concentrações de penicilina.

A redução de nitrato a nitrito em meio nitrogenado complexo, está de acôrdo com Baumann \& col. (1968a) e Gilardi (1968). Sòmente algumas amostras de $M$. polymorpha var. oxidans apresentaram esta capacidade, fato êste não observado por DeBord (1942). Já Pièchaud (1961) verificou que tôdas suas amostras determinavam aquela redução.

As amostras de Mima e Herellea estudadas no presente trabalho foram imóveis, como observado pela maioria dos autores, Travassos (1960), Gilardi (1968), Vernin \& Ciconelli (1968), Baumann \& col. (1968 a e b), Stangalini \& Pedrinazzi (1968). No entanto, Nelson \& Shelton (1965) encontraram amostras móveis e Lautrop (1961) demonstrou movimento de deslizamento na $H$. vaginicola, enquanto Baumann \& col. (1968b) verificaram movimento de expansão-contração e movimentação das células na superfície do meio sólido, tanto das amostras oxidase positivos como negativos.

As amostras de $H$. vaginicola não produziram ácido de maltose, lactose e sacarose em meio nitrogenado complexo, como também foi observado por Gilardi (1968) e outros. No entanto, o ataque à êstes carboidratos nestas condições tem sido assinalado por certos autores: Beer (1963), Brodie \& Anderson (1964). 
Fazendo-se uma apreciação dos resultados do presente trabalho em confronto com os resultados de outros autores, pode-se dizer que: Mima e Herellea são pequenos bacilos ou cocobacilos que se dispõem acs pares e até em pequenas cadeias, aeróbios estritos, Gram negativos (podendo resistir à descoloração), imóveis, não espcrulam, catalase positivos, não produzem pigmentos e não produzem indol. Mima polymorpha var. oxidans distingue-se de Mima polymorpha e Herellea vaginicola por ser oxidase positiva, não atacar nenhum carboidrato quer em meio complexo nitrcgenado, quer em meio mineral, produzir pequenas colônias em ágar e poder reduzir nitrato a nitrito. Mima polymorpha e Herellea vaginicola são oxidase negativas, produzem grandes colônias em ágar, não reduzem nitrato a nitrito, havendo ou não crescimento no meio de citrato de Koser, KCN, podendo cu não hidrolizar a gelatina. Mima polymorpha pode ser diferenciada de Herellea vaginicola porque esta última produz ácido a partir da giicose nos meios de Hugh-Leifson (1953), nitrogenado ccmplexo e em ágar inclinado lactosado a $10 \%$, quer em base nitrogenada complexa, quer $\epsilon \mathrm{m}$ base sintética.

\section{RESUMO}

No presente trabalho, os autores estudaram as propriedades morfo-bioquímicas e a sensibilidade acs antibióticos de 19 amostras de bactérias dos gêneros Mima e Herellea isoladas de material clínico e identificadas como Mima polymorpha variedade oxidans, Mima polymorpha e Herellea vaginicola.

No estudo bicquímico observcu-se que Herellea vaginicola foi oxidase negativa e em meio complexo nitrogenado, consistentemente ataca a glicose, galactose, manose, arabinose, xilose, lactose a $10 \%$ e irregularmente ataca a ramnose e a celobiose; em base sintética nitrogenada, além das atividades citadas, consistentemente produziu ácido a partir da lactose. Mima polymorpha foi oxidase negativa, não apresentando atividade glicidolítica, quer em meio complexo nitrogenado, quer em base sintética nitrogenada. Mima polymorpha var. oxidans, foi cxidase positiva, não revelando nenhuma atividade glicidolítica.

Herellea vaginicola e Mima polymorpha mostraram grande sensibilidade à gabromicina, kanamicina, neomicina, colistin, sendo que a última também foi muito sensível ao cloranfenicol e rovamicina. Mima polymorpha var. oxidans, apresentou grande sensibilidade à kanamicina, neomicina, colistin, cloranfenicol e wintomylon. 
A sensibilidade das amostras a 1 a 0,1 unidade de penicilina $/ \mathrm{ml}$, nas condições ensaiadas no presente trabalho, não foi absoluta, como a observada por Baumann, Doudoroff \& Stanier (1968a) que permitisse uma sєparação entre amostras oxidase positiva e negativa ou uma diferenciação dentro do grupo das bactérias oxidase positiva.

\section{SUMMARY}

The authors studied the morpho-biochemical characteristics and antibiotic sensitivity of 19 strains of bacteria isolated from clinical specimens and identifyed as Mima polymorpha var. oxidans, Mima polymorpha and Herellea vaginicola. The biochemical study indicated Herellea vaginicola to be oxidase negative and in complex nitrogenous media effetively utilize glucose, galactose, mancse, arabinose, xylose, $10 \%$ lactose and irregularly utilize rhamnose and cellobiose; in the synthetic base media the strains produced acid from lactose and have the same sugar oxidations as described before. Mima polymorpha was oxidase-negative and failed to utilize the carbohidrates tested in either the complex nitrogenous media or the synthetic base media. Mima polymorpha var. oxidans was oxidase-positive and failed to utilize the carbohydrates tested.

The Herellea vaginicola and Mima polymorpha was very susceptible to gabromycin, kanamycin, neomycin, colistin and the former was very sensitive to chloranphenicol and rovamycin. Mima polymorpha var. oxidans presented high sensibility to kanamycin, neomycin, colistin, chloranphenicol and nalidixic acid.

With the results obtained by the sensibility of strains to the 1 and 0,1 unity of penicillin by milliliter, it was impossible to separate the oxidase-positive and oxidase-negative strains in discordance with the data obtained by Baumann, Dodoroff \& Stanier (1968 a).

\section{AGRADECIMENTO}

Agradecemos ao Dr. Robert E. Weaver, in Charge, Special Bacteriology Lab., Clinical Bacteriology Unit, Bacteriology Section, do Department of Health, Education, and Welfare, Public Health Service, National Comunicable Disease C€nter, C.D.C., Atlanta, Georgia, por haver gentilmente confirmada a identificação de algumas de nossas amostras de Mima e Herellea. 


\section{REFERÊNCIAS BIBLIOGRAFICAS}

ANdureau, A., 1940 - Etude du genre Moraxella. Ann. Inst. Pasteur, 64: 126166.

Baumann, P., Doudoroff, M. \& StaIner, R. Y., 1968a - Study of the Moraxella Group I - Genus Moraxella and the Neisseria catarrhalis group. J. of Bact., 95: 58-73.

BaumanN, P., Doudoroff, M. \& Stainer, R. I., 1968b - A study of the Moraxella Group. II - Oxidative-negative species (genus Acinetobacter). J. of Bact. 95: $1520-1541$.

BEER, H., 1963 - Zur Diagnostik Gram negativer, aerober Stäbchen. Pathol. Microbiol., 26: 607-634.

Breed, R. S., Murray, E. G. D. \& Hitchens, H., 1948 - "Bergey's Manual of Determinative Bacteriology", 7 th ed., Williams and Wilkins Co., Baltimore, $\mathrm{Md}$.

Breed, R. S., Murray, E. G. D. \& Smith, N. R., 1957 - "Bergey's Manual of Determinative Bacteriology", 7 th. ed., Williams and Wilkins Co., Baltimore, $\mathrm{Md}$.

BRET, A. J. \& DURRIEUX, R., 1961 - Infections vaginales à Moraxella, Identifications et consequences neonatales. Presse Med., 69: 2002-2005.

BRISOU, J., 1953 - Essai sur la systématique du genre Achromobacter. Ann. Inst. Pasteur, 84: 812-814.

BRISOU, J. \& PRÉvot, A. R., 1954 - Étude de şystématique bacteriène. X - Révision des especes reunnis dans le genre Achromobacter. Ann. Inst. Pasteur, 86: 722.

Brodie, J. \& Henderson, A., 1963 - Mima polymorpha infection. J. Clin. Pathol. 16: 49.

Brodie, J. \& Henderson, A., 1964 - Further observations on Mima polymorpha and Achromobacter (Bacterium) anitratum. J. Clin. Pathol., 17: 513-516.

BROOKE, R. \& MaRkUS S., 1951 - The occurence of B5W (B. anitratum) strains in Denmark. Acta Pathol. Microb. Scand. 28: 338-342.

CASEllas, J. M., 1968 - Contribuição ao estudo de bactérias Gram negativas, aeróbias, produtoras de ácidos ônicos (Grupo Lwoffi-glucidolytica). Tese apresentada ao Instituto de Microbiologia da Universidade Federal do Rio de Janeiro, para obtenção do grau de Mestre em Microbiologia. Rio de Janeiro, 1968.

ChILton, M. L., 1946 - A presumptivem medium for differentiation Paracolon from Salmonella cultures. J. Lab. Clin. Med., 31: 824-827.

Costa, G. A. \& SolÉ-Vernin, C., 1955 - Sôbre u'a modificação do meio de Monteverde. Mem. Inst. Oswaldo Cruz, 53, (1) : 105-114.

DEBORD, G. G., 1939 - Organisms invalidating diagnosis of gonorrhea by smear method. J. Bact., 38: 119-120.

DEBoRD, G. G., 1942 - Descriptions of Mimeae Trib. nov. with three genera and three species and two new species of Neisseria from conjuntivitis and vaginitis. Iowa State Coll. J. Sci., 16: 471-480.

DEBORD, G. G., 1948 - Mima polymorpha in meningitis. J. Bacteriol. 55: 764765.

ELLIS, E. M., 1961 - The recovery of Bacterium anitratum (B5W) from animais. Am. J. Vet. Res., 22: 610. 
FAUST, J. \& Hood, M., 1949 - Fulminating septicemia caused by Mima polymorpha. Am. J. Clin. Pathol., 19: 1143.

GILARDI, G. L., 1968 - Morphological and Biochemical differentiation of Achromobacter and Moraxella (DeBord's Tribe Mimeae). Appl. Microbiol., 16: 33-38.

Gilick, L. M., Moran, G. P., Coleman, J. M. \& O'Brien, G. F., 1959 - Lobar pneumonia with bacteremia caused by Bacterium anitratum. Am. J. Med., 27: 183.

HenRIKSon, S. D., 1951 - Moraxella duplex, var. non liquefaciens, as a cause of bronchial infection. Acta Pathol. Micr. Scand. 29: 258-262.

HUGH, R. \& LeIfSON, E., 1953 - The taxonomic significance of fermentative versus oxidative metabolism of carbohydrates by various Gram negative Bactéria. J. Bacteriol., 86: 24-26.

Inclan, A. P., Massey, L. C., Crook, B. G. \& Bell, J. S., 1965 - Organisms of the Tribe Memeae. Incidence of isolation and clinical correlation at the city of Menphis. Hospitals South. Med. Journ. 58: 1261-1266.

IRving, W. R. \& Hermick, W. C., 1967 - The bacteria Mima-Herellea. Isolation and clinical significance in a general Hospital. Am. J. Clin. Path. 47: 729-733.

Jordan, E. O. \& Harmon, P. H., 1928 - A new differential medium for the paratyphoid group. J. Infec. Des., 42: 238-241.

KAUFFMANN, F. - In the Enterobacteriaceae, Second revised edition. Ejnar Mensksgaard Publisher, Copenhagen, 1954.

Kenner, B. A. \& Kobler, P. W., 1953 - Member of the Tribe Mimeae isolated from river water. J. Bacteriol. 72: 870.

KING, O. H., Copeland, G. D. \& Berton, W. M., 1963 - Cardiovascular lesions of the Mimeae organisms. Am. J. Med., 35: 241-250.

KOBURGER, J. A., 1964 - Isolation of Mima polymorpha from dairy-products. J. Dairy Sci. 47: 646.

Kovacs, N., 1956 - Identification of Pseudomonas pyocyanea by oxidase reaction. Nature, 178-703.

LAUTROP, H., 1931 - Bacterium anitratum transferred to the genus Cytophaga. Inter. Bull. Bacteriol. Nomencl. Taxon., 11: 107-108.

Leduc, A., Fontaine, J., Brazeau, M., Panissét, L. C. \& Montplaisir, S., 1969 Le Bacteriologiste clinique face à un problème de classification: Moraxella, Achromobacter, Acinetobacter. Canadian J. of Microbiol., 15: 655663.

Lemoigne, M., Girard, H. \& Jacobelil, G., 1952 - Bactérie du sol utilisant fàcilment le 2-3 butanodiol. Ann. Inst. Pasteur, 82: 389-398.

Lingelsheim, W. von, 1908 - Bieträge zur Atiologie der epidemischen geniokstasse nach den Ergebnissen der letzten jahre. J. Hyg., 59: 457-483.

LiU-KUeI-Chih, LI-ChIA-Hung \& ChI-Chang-TSaI, 1966 - Isolation and identification of organisms of $B$. anitratum group. Acta. Micr. Sinica, 12: 1-6.

Lothe, F. \& GRIFFin, F., 1965 - Bacterium anitratum and Mima polymorpha infections in Uganda. J. Clin. Path., 18: 301-306.

Lwoff, A., 1939 - Révision et démenbrement de Hémophilae. Le genre Moraxella nov. gen. Ann. Inst. Pasteur, 68: 168. 
Minzter, A., 1956 - Human infection caused by Mimeae organisms: report of a case of presumably healed bacterial endocarditis due to Herellea vaginicola. Arch. Internal. Med., 98: 352-355.

Moeller, V., 1954 - Diagnostic use the Braun KCN test within the Enterobacteriaceae. Acta path. et Microbiol. Scand. 34: 115-126.

NeLson, J. D. \& Shelton, S., 1265 - Cultural, biochemical and immunological properties of Mima, Herellea and Flavobacterium species. Appl. Microbiol., 13: 801-807.

Olafsson, M., LeE, ‘Y. C. \& Abernathy, T. J., 1958 - Mima polymorpha miningitis: a report of a case and review of the literature. New Engl. J. Med., $258: 465$.

Pedrinazzi, R. \& Stangalini, A., 1968 - Su alcune Affezioni infantili con emocultura positiva par Mima polymorpha. Giorn. mal. Inf. Parass., 20: 935937.

FICKETT, M. J. \& MANCLARK, D. R., 1965 - Tribe Mimeae. An illegitimate epittet. The Amer. J. of Clin. Path., 43: 161-165.

PiÉchaud, D., PiÉChaud, M. \& Second, L., 1951 - fitude de 26 souches de Moraxella lwoffi. Ann. Inst. Pasteur., 80: 97.

PiÉChaUd, D., PiÉChadd, M. \& SECONd, L., 1956 - Varietés proteolytiques de Moraxella lwoffi et de Moraxella glucidolytica (Bact. anitratum). Ann. Inst. Pasteur, 90: 517-522.

Prakash,.O., Balakrinshinam, P., Silvarajan, K. \& SeTh, R., 1963 - Isolations of strains resembling Bacterium anitratum from patients in Dehli. Indian J. Microb., 3: 23-28.

Roвy, C., 1954 - A propos d'un cas de méningite cerebro-spinale à Moraxella lwoffi observé au Vietnan. Bull. Soc. Path. Ex., 47: 218-222.

SchaUb, I. G. \& HAUBER, F. D., 1948 - A biochemical and serological study of a group of identical unidentifiable Gram-negative bacilli from human sources. J. Bacteriol., 56: 379-385.

Solé-Vernin, C. \& Ciconelli, A. J., 1968 - Uretrite "gonococica" e a chamada tribo Mimeae, DeBord, 1942, em Ribeirão Prêto, SP. O Hospital, 73: 234243.

SNODGRASS, C. J. \& KobURGer, J. A., 1967 - The isolation and characterization of the tribe Mimeae in Foods tuffs. J. of Food Science, 32: 289-591.

Stangalini, A. \& Pedrinazzi, R., 1968 - Ricerca di microorganismi della tribu Mimeae nelle fauci e nelle feci di banbini sonie Malati. Giornale di Malattie Infettive e Parass., 20: 923-934.

Stuart, C. A., Formol, S. \& MCGANN, V., 1949 - Further studies of B5W an anaerogenic group in the Enterobacteriaceae. J. Infect. Diseases, 84: 235239.

Svihus, R. H., Lucere, E. M., Mikolajozyk, R. J. \& Carter, E. E., 1961 - Gonorrhea-like syndrome caused by penicillin resistant Mimeae. J. A. M. A., 177: 121-124.

Travassos, L. R., 1960 - Isolamento e identificação de bactérias da tribo Mimeae (DeBord, 1942). An. Microbiol., 20: 105-130. 